\title{
Influence of draw restraining force on the springback in advanced high strength steels
}

\author{
R. Padmanabhan ${ }^{1}$, Jihyun Sung ${ }^{2}$, H. Lim², M.C. Oliveira ${ }^{1}$, L.F. Menezes ${ }^{1}$, R.H. Wagoner ${ }^{2}$ \\ ${ }^{I}$ CEMUC, Department of Mechanical Engineering \\ University of Coimbra, Polo II e-mail: \{padmanabhan, marta.oliveira, luis.menezes\}@dem.uc.pt \\ Coimbra 3030 788, Portugal \\ ${ }^{2}$ Department of Materials Science and Engineering \\ The Ohio State University, 177 Watts Hall \\ 2041 College Road, Columbus \\ OH 43210-1179, USA \\ e-mail: \{sungj, lim,wagoner\}@matsceng.ohio-state.edu
}

\begin{abstract}
Draw beads are used in sheet metal forming processes to regulate material flow and achieve higher quality in the parts. The draw beads impose draw restraining force on the blank which eliminates defects such as wrinkling, tearing and reduces springback. In a draw-bend test, the draw restraining force is imitated by the back force applied through a hydraulic ram. As the back force increases, large strain is induced which reduces springback tendency. This study evaluates the influence of back force on the springback behavior in advanced high strength steel (AHSS). Three grades of dual-phase steel, namely DP600, DP800, DP980, are used with normalized back forces ranging from 0.5 to 1.1. The springback decreases as the back force increases. Anticlastic curvature as well as curl radius has significant influence on the springback behavior of dual phase steels.
\end{abstract}

Key words: Forming, AHSS, Springback, Draw-bend test, Anticlastic curvature

\section{INTRODUCTION}

Advanced high strength steels (AHSS) are engineered to have both high strength and enhanced formability characteristics. Yet, the formed components undergo springback due to elastic recovery after removal of the forming tools. This severely affects the dimensional accuracy of the part. Many techniques have been evolved to deal with springback. A simple approach is to design forming tools that compensate for springback [1]. As the springback increase, its variability will also increase that result in the die correction estimation difficulties, especially when the part has complex geometry [2]. An effective approach to reduce springback is by attaining adequate strain levels in the part. This can be achieved by utilizing draw beads to induce large strain and reduce elastic recovery process in the part [3]. Dual phase steels have excellent ductility and work-hardening rate resulting in a superior strength-ductility balance. Higher strength levels and improved formability are achieved in the parts due to increased values of work-hardening exponent of the dual-phase steels. This in turn increases problems such as springback, higher loads on the forming tools, etc. This study focuses on the influence of drawing restraining force on the springback characteristics of the dual-phase steel using draw-bend test. Draw-bend tests imitate typical forming procedure involving tensile loading, bending, and unbending as the specimen is drawn over the roller [4]. As the sheet tension is increased, through a hydraulic actuator in the draw-bend tester, springback reduces at different rates for different materials [5].

\section{EXPERIMENTAL PROGRAM}

\subsection{Material}

Table 1. Material Properties

\begin{tabular}{llll}
\hline Property & DP600 & DP800 & DP980 \\
\hline Young's Modulus (GPa) & 200 & 210 & 210 \\
Poisson Ratio & 0.3 & 0.3 & 0.3 \\
Yield Stress (MPa) & 362 & 512 & 578 \\
UTS (MPa) & 651 & 807 & 979 \\
Thickness (mm) & 1.44 & 1.44 & 1.44 \\
\hline
\end{tabular}

Three grades of dual phase steel, namely DP600, 
DP800, DP980, were used in this study. Some material properties are listed in table 1.

\subsection{Draw-bend test specimen}

The draw-bend test specimens were cut along the rolling direction for $710 \mathrm{~mm}$ length and $25.4 \mathrm{~mm}$ width. In addition, $50.1 \mathrm{~mm}$ wide specimens made from DP600 steel were used for comparison.

\subsection{Draw-bend test procedure and Parameters}

The draw-bend tester is capable of imposing longer drawn distance and various front and back forces on the specimen $[6,7]$.

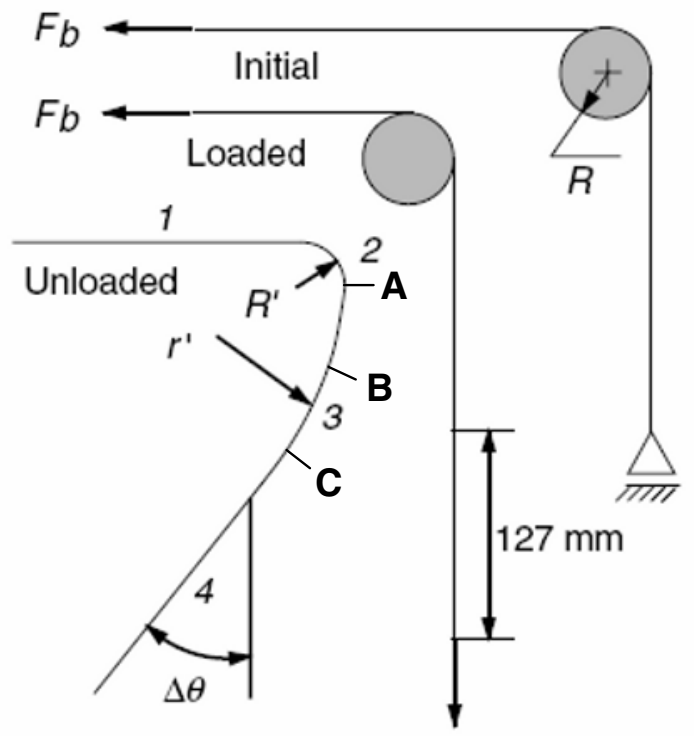

Fig. 1. Schematic of the stages of the draw-bend test and unloaded specimen geometry [8]

The specimen was mounted between the front and back actuators and a pretension (back force) was applied using the back actuator. The back force was varied between $50 \%$ yield strength of the material to $110 \%$ yield strength at regular intervals of $10 \%$. Immediately after the application of back force, the specimen is drawn to a distance of $127 \mathrm{~mm}$ at a rate of $25.4 \mathrm{~mm}$ per second. At the end of drawing, the specimen was released from the tester and its profile was traced on paper. The time between release from the tester and tracing was close to 30 seconds. The anticlastic curvature $\left(\mathrm{R}_{\mathrm{a}}\right)$ and curl radius $\left(\mathrm{r}^{\prime}\right)$ were measured using a Kreon (KZ50) LASER device. They were measured on each specimen in region 3, at a position $76 \mathrm{~mm}$ from the location of the boundary between region 1 and region 2 (fig. 1). The $\mathrm{R} / \mathrm{t}$ ratios under analysis are close to 4.6 and 7.9 for the 6.4 and $11.1 \mathrm{~mm}$ roller radii, respectively. Minimum friction (free rolling) was used in all experiments.

\section{RESULTS AND DISCUSSION}

\subsection{Springback Angle}

Figure 2 shows the springback angle $(\Delta \theta)$ for different materials at different back forces, ranging from $50 \%$ yield strength to $110 \%$ yield strength for a roller radius of $6.4 \mathrm{~mm}$. As the back forces increase, the springback angle reduces. The rate of reduction in springback angle increases with increasing material strength. The springback angle at high back forces is controlled by anticlastic curvature [9]. Higher back forces accentuate anticlastic curvature, which in turn increases the moment of inertia of the specimen cross section, thus reducing springback. At low back forces $(\mathrm{Fb})$, the springback angles for increasing material strength are higher. Beyond $\mathrm{Fb}=$ 0.8 this trend reverses, and the springback angles for increasing material strength become smaller.

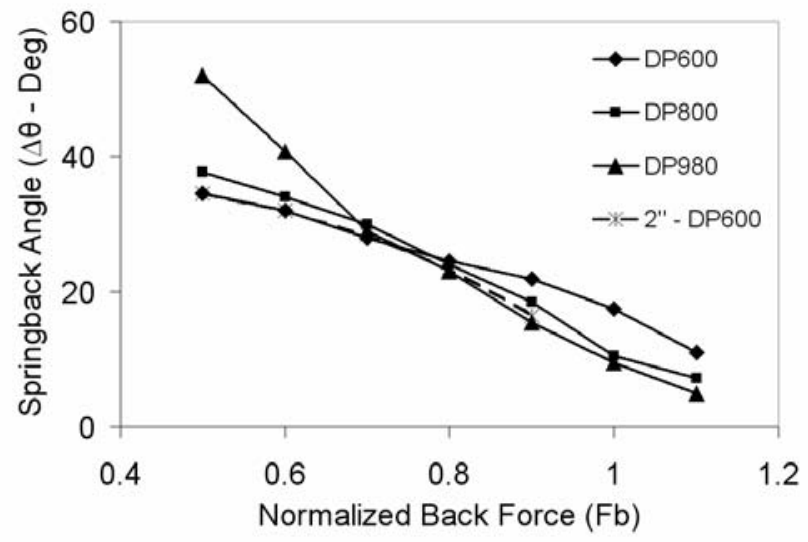

Fig. 2. Springback angle obtained using $R=6.4 \mathrm{~mm}$

To determine the influence of specimen width on springback, specimens made of DP600 steel were tested in two widths: $50.1 \mathrm{~mm}$ and $25.4 \mathrm{~mm}$. Springback angle results for these specimens are also presented in figure 2. At low back forces, both specimens produced same springback while back forces beyond $80 \%$ yield strength produced considerable deviations in springback angle. Due to high contact forces, back forces more than $90 \%$ of yield strength cannot be tested for wider specimens. Figure 3 shows the springback angle for various back forces using a roller radius of $11.1 \mathrm{~mm}$. As the back forces increase, the springback angle reduces with marginal difference in the rate of reduction. 


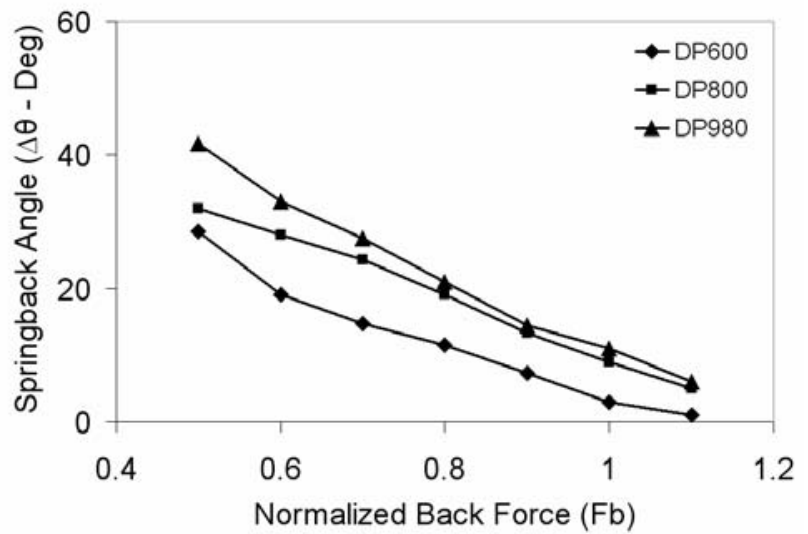

Fig. 3. Springback angle obtained using $R=11.1 \mathrm{~mm}$

The springback angle obtained using $11.1 \mathrm{~mm}$ roller radius is less than that obtained by using a roller radius of $6.4 \mathrm{~mm}$. Over the range of back forces DP980 produced more springback compared to DP800 and DP600 respectively.

\subsection{Anticlastic curvature}

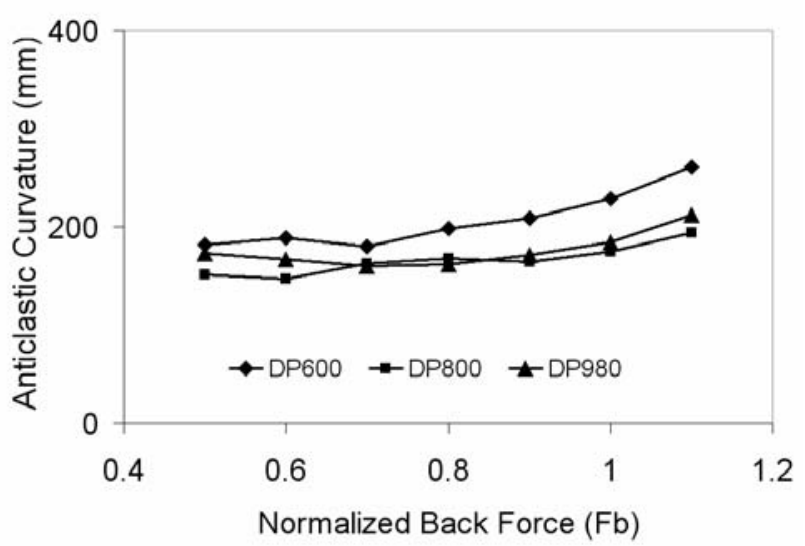

Fig. 4. Anticlastic radius of curvature using $R=6.4 \mathrm{~mm}$

Anticlastic curvature develops due to differential lateral contraction through thickness of the sheet under the principal bending action. It depends on the magnitude of the back force and the roller radius. As the back force increases in the sheet, the springback angle can drop drastically due to the appearance of anticlastic curvature. Figure 4 shows the increase in anticlastic radius of curvature as the back forces increase, using a roller radius of $6.4 \mathrm{~mm}$. As the relative back force increases beyond 0.7 , significant increase in the anticlastic curvature is observed, especially in DP600 steel.

The trend is similar for DP600 steel using $11.1 \mathrm{~mm}$ roller radius, as shown in Fig. 5. In DP800 specimens, the anticlastic radius of curvature remained almost the same for all back forces and it reduced marginally in DP980 specimens. In higher grade steels, especially DP980, the anticlastic radius of curvature reduces due to the development of a tertiary curvature between region 2 and region 3 in figure 1. This behavior is further explained at the end of section 3.3.

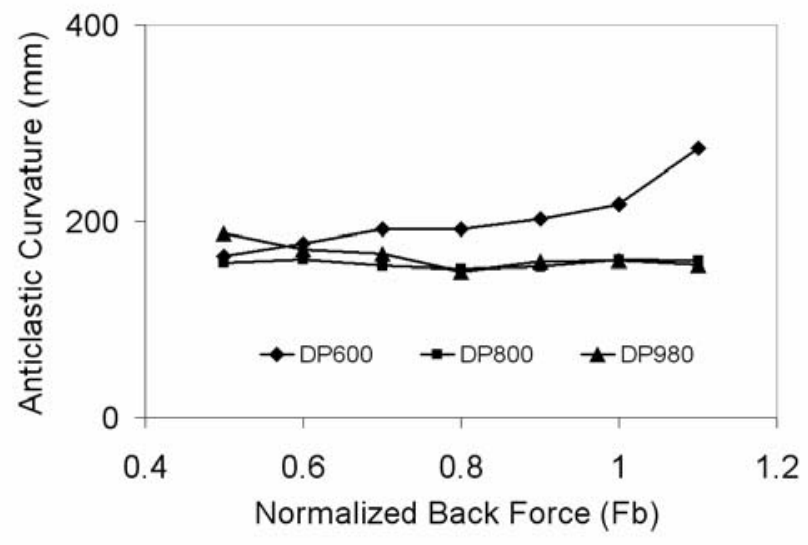

Fig. 5. Anticlastic radius of curvature using $\mathrm{R}=11.1 \mathrm{~mm}$

\subsection{Curl radius}

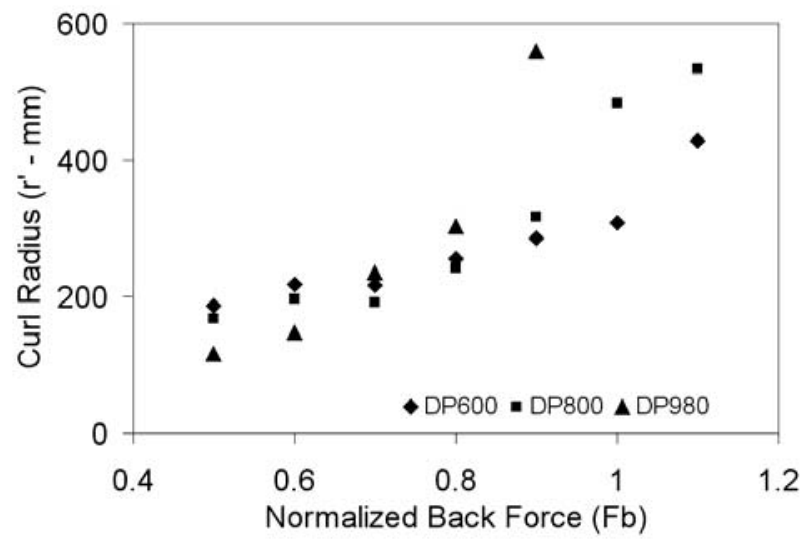

Fig. 6. Curl radius using $\mathrm{R}=6.4 \mathrm{~mm}$

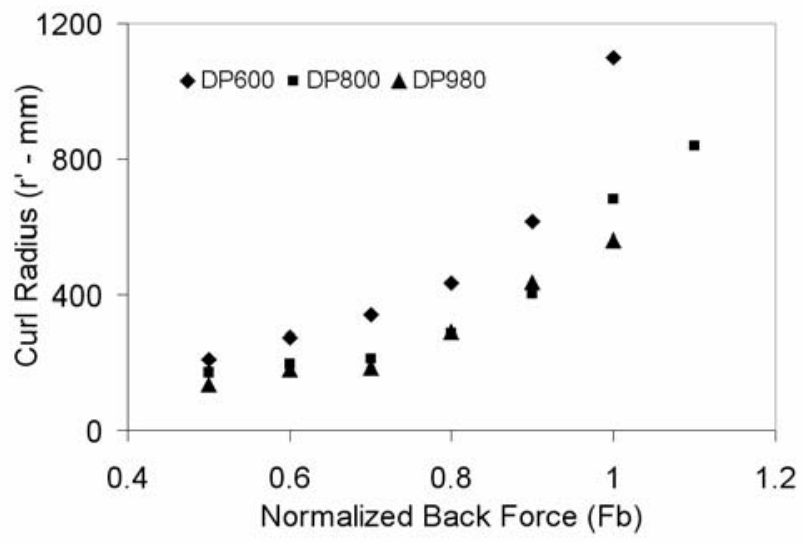

Fig. 7. Curl radius using $\mathrm{R}=11.1 \mathrm{~mm}$

The curl radius ( $\left.\mathrm{r}^{\prime}\right)$ at the region that has undergone 
bending and unbending, over an arc length of 127 $\mathrm{mm}$, is related to the springback angle. As shown in figure 6 , increasing the back force increases the curl radius. The trend is opposite to that observed for springback angle. The curl radius in DP980 increased sharply as the back force increases, while the increase is moderate in other steels. Figure 7 shows the increase in curl radius using $11.1 \mathrm{~mm}$ roller radius. The increase is similar in the three grades of steel. In DP980, as the back force increased beyond $100 \%$ yield strength, a tertiary curvature developed between region 2 and region 3 . Higher back forces, yield strength and beyond, causes prestrain in the specimen before the drawbend procedure. This increased the strength in the specimen and consequently resulted in a complex geometry after the draw-bend procedure. Figure 8 shows the profile of the draw-bend portion of the specimen as two sections, $\mathrm{AB}$ and $\mathrm{BC}$ (indicated in figure 1). As shown in Fig. 8, curvature 1 and curvature 3 have their centers on one side, and curvature 2 has its center on the opposite side. Normalized back forces beyond 1.0 result in a complex stress state in the specimen and hence an intermediate curvature is developed.

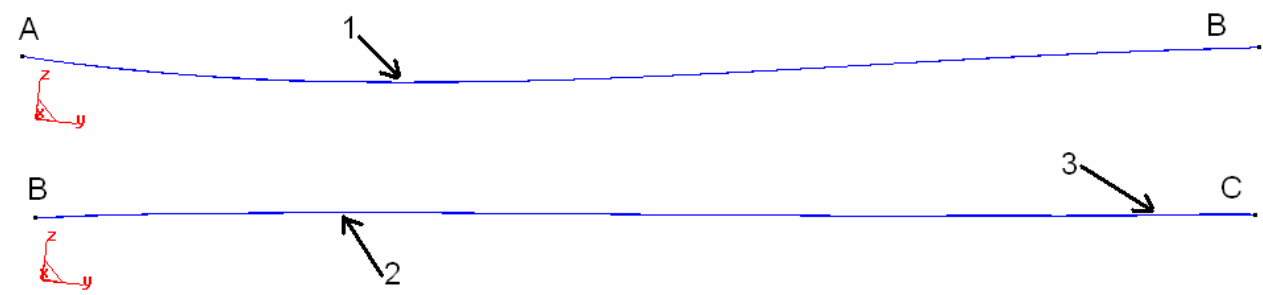

Fig. 8. Unloaded profile of the draw-bend region

\section{CONCLUSIONS}

Three grades of dual-phase steel specimens were subjected to different back forces to determine their springback behavior using two different roller radii. As the back force increase, the springback angle can drop quickly with increasing material strength. This behavior is pronounced at low $\mathrm{R} / \mathrm{t}$ ratios. Draw restraining force has significant influence on the springback; higher forces result in less springback and consequently produce dimensional stability in the formed part. Anticlastic radius of curvature and curl radius have direct implication on the springback angle in the draw-bend specimen. A tertiary curvature was observed in DP980 specimens at higher back forces.

\section{ACKNOWLEDGEMENTS}

The authors acknowledge the Ohio State University for providing material and facilities to conduct the experiments for this study. The authors from Portuguese Institution are grateful to the Portuguese Foundation for Science and Technology (FCT) for the financial support through the program POCI 2010.

\section{REFERENCES}

1. Wei Gan, R.H. Wagoner, Die design method for sheet springback, International Journal of Mechanical Sciences 46 (2004) 1097-1113.

2. M.C. Oliveira, J.L. Alves, B.M. Chaparro, L.F. Menezes, Study on the influence of work-hardening modeling in springback prediction, International Journal of Plasticity 23 (2007) 516-543.

3. J-H. Song, H. Huh, S-H. Kim, A simulation-based design parameter study in the stamping process of an automotive member, Journal of Materials Processing Technology 189 (2007) 450-458.

4. W.D. Carden, L.M. Geng, D.K. Matlock, R.H. Wagoner, Measurement of Springback, International Journal of Mechanical Sciences 44 (2002) 79-101.

5. K.P. Li, W.P. Carden, R.H. Wagoner, Simulation of Springback, International Journal of Mechanical Sciences 44 (2002) 103-122.

6. G.J. Wenzloff, T.A. Hylton, D.K. Matlock, A new procedure for the bending under tension friction test. Journal of Material Engineering and Performance, 1(5) (1992) 609-613.

7. D.W. Vallance, D.K. Matlock, Application of the bending-under-tension friction test to coated sheet steels, Journal of Material Engineering and Performance, 1(5) (1992) 685-693.

8. J.F. Wang, R.H. Wagoner, D.K. Matlock, F. Barlat, Anticlastic curvature in draw-bend springback, International Journal of Solids and Structures 42 (2005) 1287-1307.

9. L. Geng, R.H. Wagoner, Role of plastic anisotropy and its evolution on springback, International Journal of Mechanical Sciences 44 (2002) 123-148. 